\section{Looking up at the Lick}

\author{
David H. DeVorkin
}

James Lick's Monument: The Saga of Captain Richard Floyd and the Building of the Lick Observatory. By Helen Wright. Cambridge University Press: 1987. Pp. 231. £25, $\$ 32.50$.

Eye on the Sky: Lick Observatory's First Century. By Donald E. Osterbrock, John R. Gustafson and W. J. Shiloh Unruh. University of California Press: 1988. Pp. $295 . \$ 25$

BUILT in a young and vigorous California, at a time when visual refracting telescopes dominated astronomical technology, the Lick Observatory at its opening in 1888 was potentially the most powerful astronomical tool in existence. Its patron was one of the most unusual characters of post-gold rush California; its backers and builders were not astronomers, though they consulted astronomers world-wide in their planning; its instrument and dome makers, save for the firm of Alvan Clark and Sons, had never ventured anything of even remotely comparable scale; and its first director was a far from stable fellow. It is remarkable that the enterprise turned out as well as it did.

The founding years of the observatory are recalled with romantic beauty and admirable accuracy in Helen Wright's James Lick's Monument. By focusing on Captain Richard Floyd, a son of the Confederacy, and on his sense of divine service to science, Wright provides a welldocumented and valuable glimpse into an important episode of patronage, politics and pride in late-nineteenthcentury American science, including the display of national chauvinism that made it impossible for Howard Grubb, the famed Dublin instrument-maker, to bid successfully to build the telescope or dome.

The early years of life at Lick were very tough. Even during its construction, the director-designate, Edward Singleton Holden, was at odds with Floyd, the builder of the observatory and president of the Lick Trust. And once Holden gained control of the magnificent new telescope, his bright, highly capable staff did not find his direction to their liking.

The pioneer astronomical spectroscopist of Tulse Hill, Sir William Huggins, once quoted the words of a fellow astronomer upon hearing of the staff problems at Lick Observatory: "What do you expect when a few men are shut up together on the top of a mountain, and only one big telescope?" (William Huggins to George Ellery Hale, 10 December, 1892, Yerkes Observatory Library). Although that quotation is not to be found in Eye on the $S k y$, Donald Osterbrock, John Gustafson and W. J. Shiloh Unruh do deftly exploit the wealth of archival material held in the Mary Lea Shane Archives of the Lick Observatory to tell the story not only of the building of the observatory, but of its first painful years under Holden and the happier decades since. Indeed, this rich archive, collected together and established by Mary Shane, is the heart of both works reviewed here.

Though Osterbrock et al. treat Holden with more sympathy than does Wright, both paint similar portraits of the dynamics of the first years of observatory life. It took only a short time for Lick's 36-inch refractor, the largest of its type in the world and situated in the clear and dry air of 4,300-foot Mount Hamilton, to shift the geographical centre of astronomical observation to the West. For example, Huggins, locked in mortal combat with Norman Lockyer over the chemical composition of nebulae, regarded observations from Lick as the arbiter in their battles, though both ultimately interpreted the data as they saw fit.

Holden was a bitter disappointment. His best staff - James Keeler, Sherbourne Wesley Burnham and Edward Emerson Barnard - all left within six years. Keeler returned as director only after Holden was ousted, and he managed in the few years before his untimely death in 1900 to establish observational astro- physics at Lick.

Keeler's legacy was carried on in a programmatic fashion by William Wallace Campbell. Campbell embarked on a longterm stellar radial velocity programme, and encouraged his staff to maintain other cataloguing efforts, such as Robert Grant Aitken's double star measures. Programmatic observing was then the raison d'être of astronomy.

At a late point in their history, Osterbrock, Gustafson and Unruh discuss briefly the transition from general programmatic observing to individual staffinitiated projects at Lick in the 1950s. As an example of the limitations of the programmatic approach, they provide a litany of solar eclipse spectroscopic expeditions mounted by the observatory which failed to anticipate future needs. Wouldn't it have been nice, the authors muse, if Donald Menzel had been on the staff earlier than 1926, soon enough to encourage Campbell to provide sensitometry marks on his plates! Menzel required line intensities in addition to wavelengths. A student of astrophysics under Henry Norris Russell of Princeton, Menzel may well have appreciated the need for calibration earlier, but his whole programme was a result of the very recent work of Megnad Saha on ionization equilibrium. A 'Donald Menzel' was impossible circa 1900.

Thus the authors give the impression that the Lick Observatory was particularly 
conservative in its programmatic tradition, making the transition late and only with some pain. This may well be so, but Lick was representative of an age and far from unique in the often difficult and bitter process of changing to an emphasis on individual projects informed by astrophysical theory. Observatory was vital only when it exploited properly its high mountain site and clear stable air. Thus they hail Keeler's upgrade of the 36-inch Crossley reflector and his creative use of it for observational astrophysics. The Crossley remained Lick's primary tool for direct photography and nebular spectroscopy, but it was soon overshadowed by George Ellery Hale's 60-inch reflector on Mount Wilson. As other observatories built larger reflectors, Lick's status continued to slip; only with the completion of the 120-inch Shane reflector, and the recruitment of staff able to explore both the observational and conceptual edges of modern astrophysics, did it fully revive.

For the past 20 years, Lick Observatory has been the Department of Astronomy at
To Osterbrock and his co-authors, Lick

the University of California at Santa Cruz. Osterbrock and company provide a valuable narrative chronology of events that shows how and why this happened. Although at times the story is laboured more a 'who did what and when' than an intellectual journey - the staff and programmes of the observatory and how and why they changed over time are candidly and vividly portrayed.

My only complaint about Eye on the $S k y$ is that it is devoid of direct citations to sources. Writing a popular work, the authors did not wish to "clutter the text with references" (p. 274), feeling that sources cited in the aggregate in bibliographical notes should be sufficient for those motivated to dig further. More serious readers will find the practice frustrating. But that apart, both books do credit to the centenary of the Lick Observatory and are well worth reading for the complementary perspectives they provide.

David H. DeVorkin is Curator of Astronomy a the National Air and Space Museum, Smithsonian Institution, Washington, DC 20560, USA.

\section{Here, there and everywhere}

\section{Desmond King-Hele}

Infinite in all Directions. By Freeman J. Dyson. Bessie/Harper \& Row: 1988. Pp.321. \$19.95.

Freeman Dyson is among the few scientists who are comfortable roaming infinitely in all directions, and his new book lives up to its exacting title. He takes us on an exhilarating roller-coaster ride that runs from the farthest reaches of boundless space into the nutshell-world of the subatomic, and from life's origins to its present travails and faraway future. The book springs from the Gifford Lectures he gave at Aberdeen, Scotland, in 1985 under the title "In Praise of Diversity", but the material has been extended and rewritten.

Dyson begins by skipping round the physical Universe, telling us of events and ideas that appeal to him, and then offers three subtle and detailed chapters on the origin of life and its possible future. Aftet these essays on the infinite possibilities of the Universe, he turns to our "unbounded responsibilities" as custodians of life on a small planet, where we have "a heritage to cherish" and "a destiny to earn". Looking back at his own roots, he sees himself as an intellectual descendant of Richard Hakluyt, the sixteenth-century promoter of exploration; of William Blake, the prophet of freedom; and of Jules Verne, who set him "on the road to America and from there onward to Uranus".

Darting here and there as the title promises, Dyson next focuses on the idea that "quick is beautiful" in technology today: being able to react to change within three to five years is the key to success. A new and growing technology, he believes, "is usually small, quick and agile"; an overripe technology "cannot regain its lost youth". The virtues of the quick and the small re-emerge in the chapter entitled "Science and Space", and are contrasted with the vices of massive projects where the design has to be fixed ten years before the spacecraft operates. Dyson compares NASA's Hubble Telescope unfavourably with ESA's Hipparcos spacecraft. "Committees do harm merely by existing", he says, because the big and costly projects are always over-emphasized. Also committees work by extrapolation of current trends; but this is not effective for more than about ten years ahead, because "neither cleverness nor stupidity is predictable" and either may alter the climate of opinion irrevocably. So engineers need to dream, and the chapter "Engineers' Dreams" offers the committees some nightmares. Dyson's own dream is for a space mission to Uranus in 2016 by an Astrochicken, a symbiosis of plant, animal and electronic components. Launched as an egg, it will mature at its planetary destination and manoeuvre itself with the aid of a Bombardier beetle's chemical jet. Imagine a committee deliberating on that proposal!

From biological spacecraft, Dyson flips back to ponder power politics on Earth.
He likes the example of Austria, nonnuclear and neutral, and advocates the Austrianization of Germany. He hopes for a non-nuclear world, but not world government; and he is even-handed in his discussions of Star Wars and nuclear winter. These varied subjects are linked by his beliefs (apparently serious and not tongue-in-cheek) "that the universe is constructed according to a principle of maximum diversity" and that the laws of nature "are such as to make the universe as interesting as possible".

Whatever we may think of the maximum-diversity principle as a world-view, there is no denying its importance throughout this scintillating book that gives the lie to the literary wallahs who complain that scientists cannot write. And only a scientist could run over the Universe in a manner so easy and relaxed. Dyson is to be congratulated on making science interesting for an audience wider than scientists, and on writing much better than most of the literary pundits.

Some of the sparkle arises because Dyson cannot resist climbing out on a limb, and no one will agree with all that he says. For example, he candidly confesses to believing in a God "who grows with the universe and learns as it develops". For those who need a Deity, this concept of God as a super-Freeman-Dyson may perhaps be more attractive than many of the other Gods on offer in the world today. Dyson also goes out on a limb in trying to argue that science and religion are similar: this seems a libel on science, for religion has been and still is at the root of a large fraction of the world's wars, whereas science has not directly caused any, and only a few can be attributed to technological arrogance.

Differences of opinion on these wider issues are inevitable, and Dyson should not be blamed for his frank speaking. A more serious complaint, I think, is that his enthusiasm and personal touch - which together animate the book - do sometimes lead him to swallow theories rather uncritically, especially if their originators have visited him at Princeton. To mention one example, comets may possibly come from an unobservable "Oort Cloud", and this hypothetical cloud may have a "losscone" to explain periodicities. There is also a remote possibility that the Sun has a companion star (they call it Nemesis). But even the first two of these hypotheses are not "firmly based", as he says they are: they may soon evaporate like a puff of phlogiston. Enthusiasm brooks no ifs and buts. This book rides on its enthusiasms and, though the ride is pleasant, we often need to add our own ifs and buts.

Desmond King-Hele is a Deputy Chief Scientific Officer at the Royal Aircraft Establishment, Farnborough, Hampshire GU14 6TD, UK. Among other books he is author of Satellites and Scientific Research (1960) and Erasmus Darwin and the Romantic Poets (1986). 